\title{
Correlation of the Radiological Emphysema Score of Chronic Obstructive Pulmonary Disease Patients with Clinic Parameters
}

\author{
Merve Yumrukuz Senel ${ }^{1}$, Serap Duru Akcali ${ }^{2}$, Alper Dilli ${ }^{3}$ and Bahar Kurt ${ }^{2}$ \\ ${ }^{1}$ Department of Chest Diseases, Balikesir State Hospital, Balikesir, Turkey \\ ${ }^{2}$ Department of Chest Diseases, University of Health Sciences, Diskapi Ylldrrm Beyazit Training and Research Hospital, Ankara, Turkey \\ ${ }^{3}$ Department of Radiology, University of Health Sciences, Diskapi Ylldırım Beyazıt Training and Research Hospital, Ankara, Turkey
}

\begin{abstract}
Objective: To evaluate the association between the degree of emphysema on computed tomography (CT) images and disease severity, in order to predict the clinical characteristics of patients with chronic obstructive pulmonary disease (COPD).

Study Design: Cross-sectional, observational study.

Place and Duration of Study: University of Health Sciences, Diskapi Training and Research Hospital, Ankara, Turkey between January 2016 and January 2017. The analysis of the medical records of patients was performed in December 2020.

Methodology: Clinically diagnosed COPD patients were included in this study. Based on emphysema severity on CT, the patients were classified into three groups as group I $(n=59)$, group II $(n=37)$, and group III $(n=20)$, and emphysema was not present in the remaining 15 patients. The associations between emphysema severity and the GOLD stage, mMRC dyspnea score and exacerbation frequency were analysed with Chi-square test.

Results: In 131 patients, the severity and presence of emphysema was found to be significantly associated with smoking history $(p=0.034)$. However, no significant differences were observed between emphysema severity and exacerbation frequency $(p=0.512)$ and mMRC dyspnea scores $(p=0.110)$. The severity of emphysema was related with the GOLD stage $(p=0.001)$. There was also a significant association between BMI and severity of emphysema, with the severe emphysema cases tending to be underweight $(p=0.001)$.

Conclusion: CT-emphysema severity can be used to classify COPD to assist in the clinical characterisation of patients. This type of classification is important to determine the underlying pathophysiology and genomic profile of COPD.
\end{abstract}

Key Words: Chronic obstructive pulmonary disease, Computed tomography, Emphysema.

How to cite this article: Senel MY, Akcali SD, Dilli A, Kurt B. Correlation of the Radiological Emphysema Score of Chronic Obstructive Pulmonary Disease Patients with Clinic Parameters. J Coll Physicians Surg Pak 2021; 31(05):506-510.

\section{INTRODUCTION}

Chronic obstructive pulmonary disease (COPD) is the fourth leading cause of death worldwide, with gradually increasing prevalence in general population due to aging and increased risk factors exposure. ${ }^{1}$ The Global Initiative for Chronic Obstructive Lung Disease (GOLD) currently defines COPD as a common preventable and treatable disease characterised by persistent respiratory symptoms and airflow limitation due to airway and/or alveolar abnormalities usually caused by significant exposure to noxious particles orgases.

Correspondence to: Dr. Merve Yumrukuz Senel, Department of Chest Diseases, Balikesir State Hospital,

Balikesir, Turkey

E-mail:mryumrukuz@gmail.com

Received: December 26, 2020; Revised: March 30, 2021;

Accepted: April 09, 2021

DOI: https://doi.org/10.29271/jcpsp.2021.05.506
GOLD also classifies the disease according to airflow limitation together with the assessment of symptoms and exacerbation risks. It is known that spirometric measurements alone do not completely reflect the severity of COPD. ${ }^{2}$ It is also known that COPD is a very heterogenous disease, even in patients with severe airflow obstruction, symptoms can be quite mild. ${ }^{3}$ Structural lung alterations such as emphysematous parenchymal destructions and conductive airway narrowing can be one of the explanations of heterogeneity of the disease. ${ }^{4}$

In the literature, there are some controversial opinions regarding the emphysema level in patients with COPD. While some state that the severity of emphysema varies widely even in patients at the same stage of COPD, ${ }^{5}$ others suggest that the amount of emphysema increases with COPD severity. ${ }^{3}$ Emphysema is a major determinant to predict lung function decline and mortality in COPD patients independent of airflow limitation. ${ }^{6}$ Also, CTquantified emphysema in COPD patients is associated with exercise intolerance, impaired gas-exchange independent of airflow limitation, symptom scale and exacerbation risk was shown by Smithetal. ${ }^{\top}$ 
Computed tomography (CT) is a well-validated technique to visually and quantitatively assess the presence, pattern and extent of emphysema, and a standardised characterisation of COPD on CT is crucial. ${ }^{8}$ Determining COPD phenotypes related to emphysema severity can be important in properly managing the treatment and subtyping of the disease, and emphysema severity can be used as a predictor of COPD and functional impairment of the patients.

The aim of the current study was to evaluate if the degree of emphysema on CT images related with COPD severity according to GOLD stage.

\section{METHODOLOGY}

A total of 131 patients with COPD were retrospectively enrolled from the pulmonology clinic. This cross-sectional, observational study was approved by Ethics Committee of University of Health Sciences, Diskapi Yildirim Beyazit Research and Training Hospital, Ankara, Turkey on October 30, 2020 (No. 99/03) and conducted in accordance with the tenets of the Declaration of Helsinki. Patients diagnosed with bronchial asthma or bronchiectasis, those with a tuberculosis history, and those with neurodegenerative diseases, were excluded from the study.

Demographic data, body mass index (BMI), smoking history, and number of exacerbations and hospitalisations were collected. The results of pulmonary function tests and the modified Medical Research Council (mMRC) dyspnea scale scores were noted. Spirometric values were evaluated according to the GOLD guidelines. ${ }^{1}$ The COPD cases were classified as mild forced expiratory volume in one second (FEV1)/forced vital capacity (FVC) $<0.70$ and FEV1 $\geq 80 \%$; moderate $(50 \% \leq \mathrm{FEV} 1<80 \%)$; severe $(30 \% \leq \mathrm{FEV} 1<50 \%)$; and very severe (FEV1 <30\%). The pulmonary function test was performed using a Jaeger MasterLab pro device The emphysema severity of the patients was determined as described by the FleischnerSociety. ${ }^{8}$ Accordingly, the visually defined phenotypes of emphysematous destruction seen in COPD were defined and classified into three groups as centrilobular, panlobular and paraseptal emphysema. Since these abnormalities often overlap, we chose the most predominant pattern. Centrilobular emphysema was predominant among our patients, and we graded emphysema in three groups: group I if lucencies occupied $\leq 5 \%$ of a lung zone (if trace and mild centrilobularemphysema was present), group II if $>5 \%$ of a lung zone, and group III if confluent and advanced type of emphysema was present.

The correlations of emphysema severity with the GOLD stage, mMRC score, exacerbation frequency, BMI, smoking history and gender were analysed. All statistical analyses were performed using the Statistical Package for the Social Science software version 23.0 for Windows (Chicago, IL, USA). The quantitative data were presented as mean \pm standard deviation (SD) and the qualitative data as number and percentages. In addition, in order to evaluate whether an association existed between the variables, the Pearson's Chi-square test or likelihood ratio was used. The obtained data were statistically analysed, and $p \leq 0.05$ was considered statistically significant at a $95 \%$ confidence interval.

\section{RESULTS}

The study included 131 patients clinically diagnosed with COPD. The mean age of the patients was $66.3 \pm 11.2$ (39-90) years. The sample consisted of 101 males and 30 females. Of the 131 patients, 64 (48.9\%) were heavy smokers with a smoking history of $\geq 40$ pack-years, 23 (17.6\%) were light smokers with smoking history of < 40 pack-years, and 44 (33.6\%) had never smoked. The patients' data are summarised in Tablel.

Table I: Patients' clinical and demographic data.

\begin{tabular}{|l|l|}
\hline Characteristics & \\
\hline Age (mean \pm SD) (years) (range) & $66.3 \pm 11.2(39-90)$ \\
Gender, $\mathrm{n}(\%)$ & $101(77.1)$ \\
Male & $30(22.9)$ \\
Female & \\
Smoking history, $\mathrm{n}(\%)$ & $44(33.6)$ \\
Never smoked & $23(17.6)$ \\
$<40$ pack-years & $64(48.9)$ \\
$\geq 40$ pack-years & \\
\hline SD: Standard deviation & \\
\hline
\end{tabular}

Seventeen patients (13\%) had respiratory insufficiency and 45 (34.4\%) described chronic bronchitis. Twenty-six patients had GOLD stage I (19.8\%), 59 had GOLD stage II (45\%), 28 had GOLD stage III (21.4\%), and 18 had GOLD stage IV (13.7\%). Emphysema was not present in 15 patients (11.5\%) while trace and mild emphysema (group I) were observed in 59 patients (45\%), moderate in 37 (28.2\%), and confluent and advanced type of emphysema (group III) in 20 (15.3\%) patients according to the CT evaluations. The severity and presence of emphysema were significantly associated with smoking history ( $p=0.034)$. However, no significant differences were observed between emphysema severity and exacerbation frequency $(p=0.512)$ and mMRC dyspnea scores $(p=0.110)$. The severity of emphysema was associated with the GOLD stage ( $p=0.001)$. There was also a significant association between the BMls of the patients and the severity of emphysema, with the severe emphysema patients tending to be underweight ( $p=0.001)$. The data are summarised in Table ll.

\section{DISCUSSION}

COPD is a very common disease in developing and developed countries due to different etiologies such as smoking, air pollution and occupational exposure causing airflow limitation as result of abnormal inflammatory responses in small airways and parenchymal destruction of the lungs which vary from patient to patient. ${ }^{9}$ COPD is a heterogeneous disease, and spirometric results alone are not sufficient to explain the heterogeneity of the disease, ${ }^{3}$ which causes difficulties in the clinical characterisation of patients. CT is a well-demarcated technique to visualise lungs in detail to assist clinicians in performing an accurate classification and phenotyping of the disease. 


\begin{tabular}{|c|c|c|c|c|c|}
\hline Parameters & $\begin{array}{c}\text { No emphysema } \\
(n=15)(\%)\end{array}$ & $\begin{array}{c}\text { Group I } \\
(n=59)(\%)\end{array}$ & $\begin{array}{c}\text { Group II } \\
(\mathrm{n}=\mathbf{3 7})(\%)\end{array}$ & $\begin{array}{l}\text { Group III } \\
(n=20)(\%)\end{array}$ & p-value \\
\hline $\begin{array}{l}\text { GOLD } \\
\text { GOLD } 1 \\
\text { GOLD } 2 \\
\text { GOLD } 3 \\
\text { GOLD } 4\end{array}$ & $\begin{array}{l}1(6.7 \%) \\
8(53.3 \%) \\
3(20 \%) \\
3(20 \%)\end{array}$ & $\begin{array}{c}15(25.4 \%) \\
35(59.3 \%) \\
7(11.9 \%) \\
2(3.4 \%)\end{array}$ & $\begin{array}{c}6(16.2 \%) \\
13(35.1 \%) \\
11(29.7 \%) \\
7(18.9 \%)\end{array}$ & $\begin{array}{l}4(20 \%) \\
3(15 \%) \\
7(35 \%) \\
6(30 \%)\end{array}$ & $0.001^{*}$ \\
\hline $\begin{array}{l}\text { Smoking history (pack-years) } \\
\geq 40 \\
<40 \\
\text { Never-smoked }\end{array}$ & $\begin{array}{l}5(33.3 \%) \\
2(13.3 \%) \\
8(53.3 \%)\end{array}$ & $\begin{array}{c}23(39 \%) \\
12(20.3 \%) \\
24(40.7 \%)\end{array}$ & $\begin{array}{l}20(54.1 \%) \\
7(18.9 \%) \\
10(27 \%)\end{array}$ & $\begin{array}{l}16(80 \%) \\
2(10 \%) \\
2(10 \%)\end{array}$ & $0.034^{*}$ \\
\hline $\begin{array}{l}\text { Exacerbation frequency } \\
\text { (per year) } \\
\geq 2 \\
<2\end{array}$ & $\begin{array}{c}5(33.3 \%) \\
10(66.7 \%)\end{array}$ & $\begin{array}{l}19(32.2 \%) \\
40(67.8 \%)\end{array}$ & $\begin{array}{l}12(32.4 \%) \\
25(67.6 \%)\end{array}$ & $\begin{array}{l}10(50 \%) \\
10(50 \%)\end{array}$ & 0.512 \\
\hline $\begin{array}{l}\mathrm{mMRC} \\
0-1 \\
\geq 2\end{array}$ & $\begin{array}{l}6(40 \%) \\
9(60 \%)\end{array}$ & $\begin{array}{l}27(45.8 \%) \\
32(54.2 \%)\end{array}$ & $\begin{array}{l}15(40.5 \%) \\
22(59.5 \%)\end{array}$ & $\begin{array}{c}3(15 \%) \\
17(85 \%)\end{array}$ & 0.110 \\
\hline $\begin{array}{l}\text { BMI }\left(\mathrm{kg} / \mathrm{m}^{2}\right) \\
<18.5 \\
18.5-24.9 \\
25-29.9 \\
>30\end{array}$ & $\begin{array}{c}1(6.7 \%) \\
6(40 \%) \\
2(13.3 \%) \\
6(40 \%)\end{array}$ & $\begin{array}{c}4(6.8 \%) \\
12(20.3 \%) \\
24(40.7 \%) \\
19(32.2 \%)\end{array}$ & $\begin{array}{l}4(10.8 \%) \\
17(46 \%) \\
10(27 \%) \\
6(16.2 \%)\end{array}$ & $\begin{array}{c}6(30 \%) \\
11(55 \%) \\
2(10 \%) \\
1(5 \%)\end{array}$ & $0.001^{*}$ \\
\hline
\end{tabular}

With the continuous development in medical practice, researchers have developed some quantification methods for the evaluation of CT findings in COPD patients, especially in case of emphysema. In this study, the authors used the visually characterised patterns of emphysema in COPD patients as described by the Fleischner Society classification system. ${ }^{8}$ The phenotyping of COPD described in the current study may help evaluate the clinical management of the patients with COPD.

Emphysema is the permanent enlargement of airspaces distal to the terminal bronchioles and develops in about $20 \%$ of smokers. ${ }^{10}$ Today, emphysema is increasingly diagnosed due to the widespread use of CT images in clinical settings. ${ }^{11}$ There are some genetic etiological factors causing emphysema, but smoking constitutes the most important risk factor. ${ }^{12}$ COPD has a spirometric definition with the symptoms of dyspnea and chronic bronchitis in addition to some structural changes such as emphysema. However, emphysema alone is not sufficient to diagnose COPD without the other components of the disease. ${ }^{13}$ Previous studies found that smoking was related to emphysema development and COPD, which is consistent with the present results, showing that the severity and presence of emphysema were significantly associated with smoking history. Chronic inflammation caused by cigarette smoking generates small airway inflammation, and the proximal extension of this inflammation results in weakened walls in the central airways. ${ }^{14}$ Emphysema can be subdivided into centrilobular, panlobular and paraseptal groups, based on the exact location of emphysematous regions within the secondary pulmonary lobule. ${ }^{8}$ Centrilobular emphysema is the prototypical form of emphysema identified in cigarette smokers while paraseptal emphysema is also clearly related to smoking. ${ }^{15}$ Panlobular emphysema is associated with a-1 antitrypsin deficiency and seems to be uncommon in smoking-related emphysema.

Previous studies showed that emphysema severity was conversely correlated with $\mathrm{BMI}$, with more severe emphysema patients tending to be underweight, ${ }^{5,13}$ which supports the present results. A study reported that COPD patients with severe emphysema had excessive loss of tissue, including $\mathrm{BMI}$, skeletal muscle, and bone density over time and tended to require hospitalisation at a higher rate. ${ }^{16}$ It was also suggested that the identification of these patients was important since they had more exacerbations and their mortality rate was higher than COPD patients without tissue loss. In this study, we investigated the relationship of emphysema severity only with BMI, not with muscle or bone tissue loss. Further prospective studies are needed to determine this type of phenotype.

In this study, the authors did not classify the patients into the subgroups of emphysema as centrilobular, panlobular and paraseptal because there were not enough patients in the latter two groups, with the majority of the cases presenting with centrilobular emphysema. Therefore, the patients were only evaluated according to the severity of emphysema and determined how the visual score of emphysema affected the clinical presentation of the patients. According to the present results, the emphysema scores of the patients were strongly associated with the GOLD stage, but not with the dyspnea scores (mMRC) or exacerbation frequency. Although a positive correlation between emphysema severity and clinical stage has been shown in many studies, ${ }^{3,13,17}$ some authors have failed to identify such positive correlation, attributing this to the heterogeneity of the disease. ${ }^{18,19}$ According to 
GOLD, ${ }^{1}$ in addition to inflammation and narrowing of peripheral airways leading to decreased FEV1, parenchymal destruction related to emphysema results in airflow limitation. ${ }^{20}$ Currently, researchers are more interested in investigating the contribution of small airways to airflow limitation in the pathogenesis of the disease. ${ }^{21}$ This contribution of small airways can also be the reason as to why a relationship could not be established between emphysema severity and the dyspnea scores and exacerbation frequency of those patients.

The underlying pathophysiology of the disease generates clinical characteristics of the patients. Defining groups of patients that exhibit distinctive pathophysiology, prognosis and response to therapy with the systematic application of imaging techniques can help better understand the heterogeneity of COPD. ${ }^{22}$

\section{CONCLUSION}

More severe CT emphysema was found to be associated with the increased GOLD stage of COPD. Furthermore, present findings suggest that emphysema severity evaluated on CT can be used to classify the disease to assist in the clinical characterisation of patients. This type of classification is important in differentiating the underlying pathophysiology and genomic profile of COPD.

\section{ETHICAL APPROVAL:}

Before the commencement of the study, legal and ethical approval was obtained from the Institutional Review Board, University Health Sciences, Diskapi Research and Training Hospital, Ankara, Turkey.

\section{PATIENTS' CONSENT:}

Informed consents were obtained from all patients to publish their clinical data.

\section{CONFLICT OF INTEREST:}

The authors declared no conflict of interest.

\section{AUTHORS' CONTRIBUTION:}

MYS: Study design, planning the study, analysis of the results, and writing of the manuscript.

SDA: Data collection, supervision, and critical feedback.

$A D$ : Data collection, analysis of the results.

BK: Supervision and final approval of the version to be published.

\section{REFERENCES}

1. GOLD 2019. Global Strategy for the Diagnosis, Management, and Prevention of COPD. Available at: http://goldcopd.org.

2. Agustí A, Vestbo J. Current controversies and future perspectives in chronic obstructive pulmonary disease. Am J Respir Crit Care Med 2011; 184(5):507-13. doi: 10.1164/rccm.201103-0405PP.

3. Agusti A, Calverley PM, Celli B, Coxson HO, Edwards LD,
Lomas DA, et al. Characterisation of COPD heterogeneity in the ECLIPSE cohort. Respir Res 2010; 11(1):122. doi: 10.1186/1465-9921-11-122.

4. Occhipinti M, Paoletti M, Crapo JD, Make BJ, Lynch DA, Brusasco V, et al. Validation of a method to assess emphysema severity by spirometry in the COPDGene study. Respir Res 2020; 21(1):103. doi: 10.1186/s12931-020-01366-4.

5. Makita H, Nasuhara $Y$, Nagai K, Ito $Y$, Hasegawa M, Betsuyaku $\mathrm{T}$, et al. Characterisation of phenotypes based on severity of emphysema in chronic obstructive pulmonary disease. Thorax 2007; 62(11):932-7. doi: 10.1136/ thx.2006.072777.

6. Oelsner EC, Carr JJ, Enright PL, Hoffman EA, Folsom AR, Kawut SM, et al. Per cent emphysema is associated with respiratory and lung cancer mortality in the general population: A cohort study. Thorax 2016; 71(7):624-32. doi: 10.1136/thoraxjnl-2015-207822.

7. Smith BM, Jensen D, Brosseau M, Benedetti A, Coxson HO, Bourbeau J. Impact of pulmonary emphysema on exercise capacity and its physiological determinants in chronic obstructive pulmonary disease. Sci Rep 2018; 8(1):15745. doi: 10.1038/s41598-018-34014-5.

8. Lynch DA, Austin JH, Hogg JC, Grenier PA, Kauczor HU, Bankier AA, et al. CT-definable subtypes of chronic obstructive pulmonary disease: A statement of the fleischner society. Radiology 2015; 277(1):192-205. doi: 10.1148/radiol.2015141579.

9. Hogg JC. Pathophysiology of airflow limitation in chronic obstructive pulmonary disease. Lancet 2004; 364(9435): 709-21. doi: 10.1016/S0140-6736(04)16900-6.

10. Fernandes L, Fernandes Y, Mesquita AM. Quantitative computed tomography imaging in chronic obstructive pulmonary disease. Lung India 2016; 33(6):646-52. doi: 10.4103/0970-2113.192880.

11. Janssen R, Piscaer I, Franssen FME, Wouters EFM. Emphysema: looking beyond alpha-1 antitrypsin deficiency. Expert Rev Respir Med 2019; 13(4):381-97. doi: 10.1080/1747 6348.2019.1580575.

12. Gharib SA, Manicone AM, Parks WC. Matrix metalloproteinases in emphysema. Matrix Biol 2018; 73:34-51. doi: 10.1016/j.matbio.2018.01.018.

13. Smith BM, Austin JH, Newell JD, D'Souza BM, Rozenshtein A, Hoffman EA, et al. Pulmonary emphysema subtypes on computed tomography: The MESA COPD study. Am J Med 2014; 127(1):94.e7-23. doi: 10.1016/j.amjmed.2013. 09.020 .

14. Copeland CR, Nath H, Terry NLJ, Wilson CG, Kim YI, Lynch DA, et al. Paratracheal Paraseptal Emphysema and Expiratory Central Airway Collapse in Smokers. Ann Am Thorac Soc 2018; 15(4):479-84. doi: 10.1513/AnnalsATS.201709$7130 \mathrm{C}$.

15. Lynch DA, Moore CM, Wilson C, Nevrekar D, Jennermann T, Humphries SM, et al. CT-based visual classification of emphysema: Association with mortality in the COPDGene study. Radiology 2018; 288(3):859-66. doi: 10.1148/radiol.2018172294.

16. Celli BR, Locantore N, Tal-Singer R, Riley J, Miller B, Vestbo J, et al. Emphysema and extrapulmonary tissue loss in COPD: 
A multi-organ loss of tissue phenotype. Eur Respir J 2018;

51(2):1702146. doi: 10.1183/13993003.02146-2017.

17. Schroeder JD, McKenzie AS, Zach JA, Wilson CG, Curran-Everett $D$, Stinson DS, et al. Relationships between airflow obstruction and quantitative CT measurements of emphysema, air trapping, and airways in subjects with and without chronic obstructive pulmonary disease. AJR Am J Roentgenol 2013; 201(3):W460-70. doi: 10.2214/AJR.12.10102.

18. Mohsen LA, Gawad EA, Ibrahiem MA. CT quantification of emphysema: Is semi-quantitative scoring a reliable enough method? Egyptian J Radiol Nuclear Med 2014; 45(3):673-8. doi.org/10.1016/j.ejrnm.2014.03.015.

19. de Torres JP, Bastarrika G, Zagaceta J, Sáiz-Mendiguren R, Alcaide AB, Seijo LM, et al. Emphysema presence, severity, and distribution has little impact on the clinical presentation of a cohort of patients with mild to moderate COPD. Chest 2011; 139(1):36-42. doi: 10.1378/chest.10-0984.

20. Hogg JC, Chu F, Utokaparch S, Woods R, Elliott WM, Buzatu $L$, et al. The nature of small-airway obstruction in chronic obstructive pulmonary disease. N Engl J Med 2004; 350(26):2645-53. doi: 10.1056/NEJMoa032158.

21. McDonough JE, Yuan R, Suzuki M, Seyednejad N, Elliott WM, Sanchez PG, et al. Small-airway obstruction and emphysema in chronic obstructive pulmonary disease. $N$ Engl J Med 2011; 365(17):1567-75. doi: 10.1056/NEJMoa1106955.

22. Han MK, Bartholmai B, Liu LX, Murray S, Curtis JL, Sciurba FC, et al. Clinical significance of radiologic characterisations in COPD. Copd 2009; 6(6):459-67. doi: 10.3109/15412 550903341513. 